\title{
Effects of Feed Restriction and Starvation on Fatty Acid Synthesis and Oxidation of Glucose and Alanine in Carp Hepatopancreas*
}

\author{
Takafumi Shikata ${ }^{\dagger}$ and Sadao Shimeno \\ Laboratory of Fish Nutrition, Faculty of Agriculture, Kochi University, \\ Monobe, Nankoku, Kochi 783, Japan
}

(Received June 10, 1996)

\begin{abstract}
In order to investigate the effects of feed restriction and starvation on the fatty acid synthesis and the oxidation of glucose and alanine to $\mathrm{CO}_{2}$ in the hepatopancreas of carp Cyprinus carpio, the fish were fed a commercial diet at feeding rates of $100 \%, 50 \%$, and $0 \%$ (starvation) of satiation for 30 days. The rate of fatty acid synthesis from D-[U- $\left.{ }^{14} \mathrm{C}\right]$ glucose and $\mathrm{L}-\left[\mathrm{U}-{ }^{14} \mathrm{C}\right]$ alanine, the activities of lipogenic enzymes, and the levels of serum triglyceride and body lipid were decreased by feed restriction and starvation. Moreover, the rate of glucose oxidation together with the glycolytic enzyme activities was significantly low in starved fish. However, the rate of alanine oxidation was scarcely changed, and alanine was more actively oxidized to $\mathrm{CO}_{2}$ than glucose regardless of feeding rate. These results indicate that the fatty acid synthesis and glycolysis are depressed by feed restriction including starvation and suggest that amino acids are the major energy sources for the hepatopancreas regardless of feeding rate.
\end{abstract}

Key words: carp, feed restriction, starvation, fatty acid synthesis, carbohydrate metabolism, alanine metabolism

Feed consumption of fish is influenced by many factors such as water temperature, feeding frequency, and dissolved oxygen content, ${ }^{1,2)}$ and feeding rate is especially important for the management of aquaculture. However, little attention has been given to the metabolic response to feeding rate in fish. ${ }^{3-8)}$ In the previous study, ${ }^{7)}$ we examined the effect of feeding rate on the hepatopancreatic enzyme activities and body composition in carp, and showed that the lipogenic and glycolytic enzyme activities together with the body lipid content decreased with decreasing feeding rate. Based on the results, it was presumed that feed restriction depressed the fatty acid synthesis and glycolysis in the hepatopancreas of carp, but further studies were needed to ascertain whether the presumption was correct. In the present study, therefore, we investigated the effects of feed restriction and starvation on the fatty acid synthesis from glucose and alanine and the oxidation of both substrates to $\mathrm{CO}_{2}$ in the hepatopancreas of carp.

\section{Materials and Methods}

\section{Fish and Feeding Methods}

Yearling carp Cyprinus carpio purchased from a fish farmer in Nankoku City were reared on a commercial diet containing $34.5 \%$ crude protein, $4.3 \%$ crude fat, and $39.5 \%$ crude sugar on dry matter basis until used. Then the fish were placed into 150 l fiber reinforced plastic aquaria containing aerated water and were fed the commercial diet 5 times a day at a feeding rate of $2.0 \%$ during one week acclimation period. Unfiltered well water was supplied at a rate of approximately $2 / / \mathrm{min}$. At the start of the experiment, the fish averaging $63.6 \mathrm{~g}$ were divided into three aquaria with 20 fish each. The fish in one aquarium ( $100 \%$ group) were fed the commercial diet to satiation 5 times a day, and those in another aquarium (50\% group) were fed the same diet 5 times a day at a feeding rate of $50 \%$ of the $100 \%$ group. The fish in the other aquarium were starved as $0 \%$ group. The feeding trial was conducted for 30 days from May 15, 1994. Water temperature varied between 19.1 and $21.2^{\circ} \mathrm{C}$.

\section{Analytical Methods}

The fish were weighed every 10 days, and the weight gain and feed efficiency were calculated. Four fish were sampled from each group on day 20 , and the fatty acid synthesis from $\mathrm{D}-\left[\mathrm{U}-{ }^{14} \mathrm{C}\right]$ glucose and $\mathrm{L}-\left[\mathrm{U}-{ }^{14} \mathrm{C}\right]$ alanine and the oxidation of both substrates to ${ }^{14} \mathrm{CO}_{2}$ in the hepatopancreas slices were determined by the methods described previously. ${ }^{9)}$ The slices were incubated at $23^{\circ} \mathrm{C}$.

At 15 to $17 \mathrm{~h}$ after the last feeding, six fish were sampled from each group, and the levels of serum triglyceride, free fatty acid, and free amino acid and the activities of hepatopancreatic phosphofructokinase (PFK, EC 2.7.1.11), pyruvate kinase (PK, EC 2.7.1.40), alanine aminotransferase (GPT, EC 2.6.1.2), glucose-6-phosphate dehydrogenase (G6PDH, EC 1.1.1.49), phosphogluconate dehydrogenase (PGDH, EC 1.1.1.44), and NADP-dependent malate dehydrogenase (NADP-MDH, EC 1.1.1.40) were assayed by the methods described previously. ${ }^{7,10,11)}$ The lipid contents of whole body and hepatopancreas were determined by extraction with ethyl ether.

Data of serum component level, enzyme activity, and

\footnotetext{
* Regulation of Carbohydrate Metabolism in Fish-XXX.

${ }^{\dagger}$ Present address: Ishikawa Prefecture Fisheries Research Center, Ushitu, Noto, Ishikawa 927-04, Japan.
} 
radioisotope experiment on individual fish were subjected to one-way analysis of variance and Duncan's new multiple range test to determine significant differences between means. ${ }^{12)}$

\section{Results}

\section{Growth and Body Lipid Content}

As shown in Table 1, the average weight gain in the $50 \%$ group was markedly lower than that in the $100 \%$ group, while the feed efficiency did not show marked reduction in spite of $50 \%$-feed restriction. The fish in the $0 \%$ group lost $14 \%$ of their initial body weight during the starving period. The lipid contents of whole body and hepatopancreas decreased with decreasing feeding rate.

\section{Serum Components}

Triglyceride level was decreased by feed restriction, and its level in the $0 \%$ group was about $1 / 10$ of that in the $100 \%$ group (Fig. 1). Free fatty acid level was lower in the $50 \%$ and $0 \%$ groups than in the $100 \%$ group. Free amino acid level did not change so much.

\section{Hepatopancreatic Enzymes}

As shown in Fig. 2, the activities of lipogenic enzymes, G6PDH, PGDH, and NADP-MDH, were significantly decreased by feed restriction, and the activities in the $0 \%$ group were $1 / 4-1 / 7$ of those in the $100 \%$ group. On the other hand, the activities of glycolytic enzymes, PFK and PK, were scarcely lowered by 50\%-feed restriction, while both enzyme activities were significantly low in the $0 \%$ group. GPT activity was depressed by feed restriction and starvation, but its activity did not differ so much between the $50 \%$ and $0 \%$ groups.

\section{Radioisotope Experiments}

The rates of fatty acid synthesis from glucose and alanine were drastically decreased with decreasing feeding rate, and they were negligible in the $0 \%$ group (Fig. 3). On the other hand, the rate of glucose oxidation was significantly decreased in proportion to feeding rate, while that of alanine oxidation was scarcely affected by the feeding rate.

Table 1. Growth and lipid content of the fish reared at different feeding rate for 30 days

\begin{tabular}{lccc}
\hline Group: & $100 \% * 1$ & $50 \%$ & $0 \%$ \\
\hline Daily feeding rate (\%) & 2.41 & 1.24 & 0 \\
Average body weight (g) & & & \\
$\quad$ Initial & 63.6 & 63.8 & 63.7 \\
$\quad$ Final & 86.3 & 73.7 & 55.0 \\
Average weight gain (g) & 22.7 & 9.9 & -8.7 \\
Feed efficiency (\%) & 42.0 & 38.5 & - \\
Lipid content (\%) & & & \\
$\quad$ Whole body*2 & 6.6 & 4.8 & 1.8 \\
$\quad$ Hepatopancreas & & 2.3 & 1.4 \\
\hline
\end{tabular}

* This group was fed a commercial diet to satiation.

* 2 Pooled sample for 3 fish.

*3 Pooled sample for 10 fish.
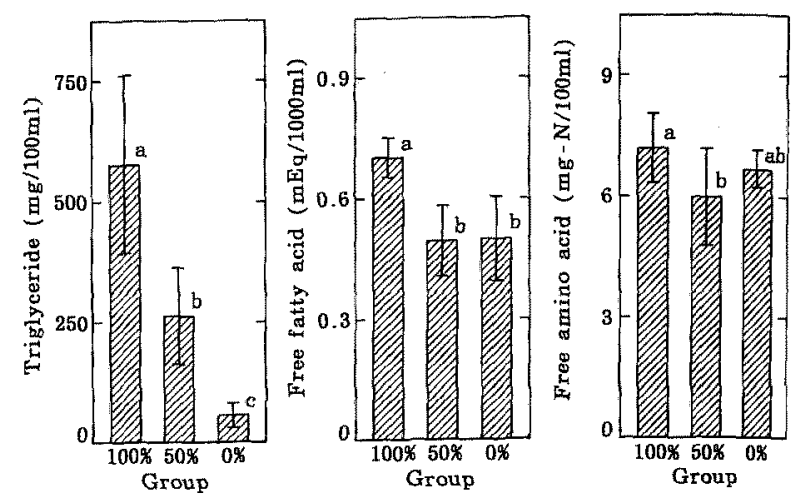

Fig. 1. Effects of feed restriction and starvation on the serum component levels.

Values are means $\pm \mathrm{SD}$ for 6 fish. Means with different superscript letters are significantly different $(P<0.05)$.
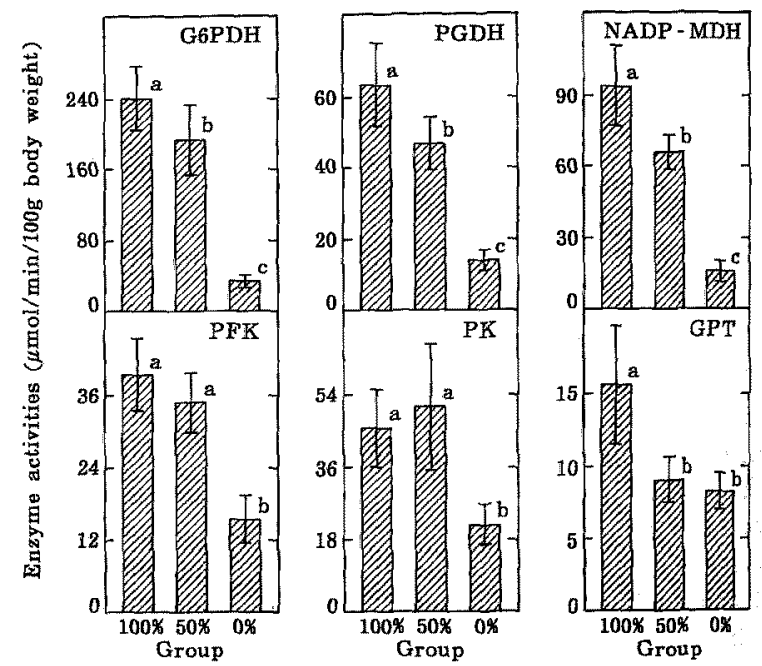

Fig. 2. Effects of feed restriction and starvation on the hepatopancreatic enzyme activities.

$V$ alues are means $\pm S D$ for 6 fish. Means with different superscript letters are significantly different $(P<0.05)$.

\section{Discussion}

The results of radioisotope experiments clearly indicate that the fatty acid synthesis in the hepatopancreas is markedly depressed by feed restriction including starvation. This is supported by the results that the lipogenic enzyme activities (G6PDH, PGDH, and NADP-MDH) significantly decreased in proportion to the feeding rate. Since these lipogenic enzymes play an important role in the generation of reducing equivalent (NADPH) for fatty acid synthesis, ${ }^{13,14)}$ the low reproduction rate of NADPH may cause the decreased fatty acid synthesis. Furthermore, as shown in Fig. 3, the rate of fatty acid synthesis from alanine was markedly higher than that from glucose regardless of feeding rate. This result supports the opinion that amino acids are the major carbon sources for fatty acid synthesis. ${ }^{15-177}$ Therefore, the depression of fatty acid synthesis is probably caused by the insufficiency of available amino acids 

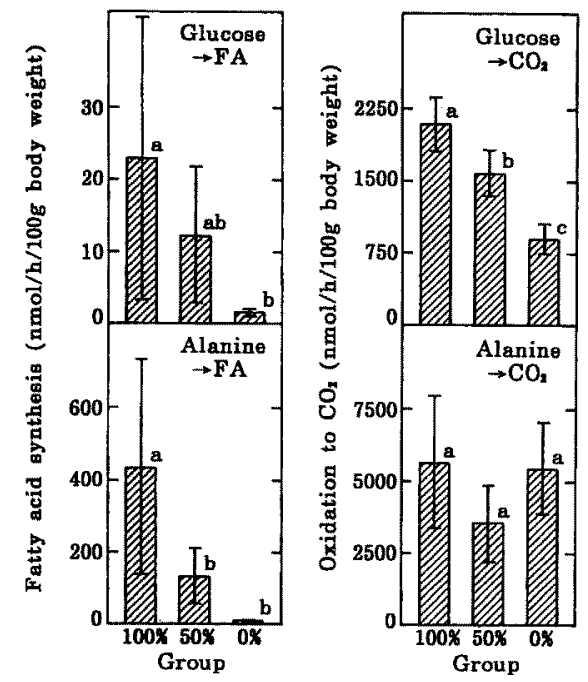

Fig. 3. Effects of feed restriction and starvation on the fatty acid synthesis from $\mathrm{D}-\left[\mathrm{U}-{ }^{14} \mathrm{C}\right]$ glucose and $\mathrm{L}-\left[\mathrm{U}-{ }^{14} \mathrm{C}\right]$ alanine and the oxidation of both substrates to ${ }^{14} \mathrm{CO}_{2}$ in the hepatopancreas.

Values are means $\pm S D$ for 4 fish. Means with different superscript letters are significantly different $(P<0.05)$.

due to feed restriction. In addition, the decreased fatty acid synthesis partly accounts for the reductions of body lipid and serum triglyceride.

In the previous study, ${ }^{7)}$ we found that the glycolytic enzyme activities in the hepatopancreas of carp decreased with decreasing feeding rate. In the present study, the activities of glycolytic enzymes (PFK and PK) were significantly low in the starved fish. Moreover, the rate of glucose oxidation decreased in proportion to feeding rate. These findings indicate that the hepatopancreatic glycolysis is depressed by severe feed restriction such as starvation.

Alanine is one of the most important amino acids as an energy source for liver, regardless of fish species. ${ }^{15)}$ Under our experimental conditions, the rates of alanine oxidation in the satiated, restricted, and starved fish were 2.7, 2.3, and 6.0-fold higher than those of glucose oxidation, respectively. This indicates that alanine is more important as energy source for the hepatopancreas than glucose, and its importance is increased by starvation. Similarly, active oxidation of alanine and glutamic acid has been reported in the whole body of carp. ${ }^{17.18)}$

We concluded that the fatty acid synthesis and glycolysis in the hepatopancreas are strongly depressed by feed restriction including starvation and amino acids are the major energy sources for the hepatopancreas regardless of feeding rate. Under restricted feeding conditions, more parts of dietary energy is probably appropriated for the maintenance of essential body function rather than the biosynthesis of nonessential component such as depot fat. Hence, the process of fatty acid synthesis seems to play an important role in the control of overall energy metabolism of carp.

\section{References}

1) J. R. Brett and T. D. D. Groves: Physiological energetics, in "Fish Physiology" (ed. by W. S. Hoar, D. J. Randall, and J. R. Brett), Vol. 8, Academic Press, London, 1979, pp. 279-352.

2) J. R. Brett: Environmental factors and growth, in "Fish Physiology" (ed. by W. S. Hoar, D. J. Randall, and J. R. Brett), Vol. 8, Academic Press, London, 1979, pp. 599-675.

3) R. L. Walzem, T. Storebakken, S. S. O. Hung, and R. J. Hansen: Relationship between growth and selected liver enzyme activities of individual rainbow trout. J. Nutr., 121, 1090-1098 (1991).

4) T. Storebakken, S. S. O. Hung, C. C. Calvert, and E. M. Plisetskaya: Nutrient partitioning in rainbow trout at different feeding rates. Aquaculture, 96, 191-203 (1991).

5) S. S. O. Hung, F. S. Conte, and E. F. Hallen: Effects of feeding rates on growth, body composition and nutrient metabolism in striped bass (Morone saxatilis) fingerlings. Aquaculture, 112, 349361 (1993).

6) A. Kiessling, K.-H. Kiessling, T. Storebakken, and T. Àsgård: Changes in the structure and function of the epaxial muscle of rainbow trout (Oncorhynchus mykiss) in relation to ration and age II. Activity of key enzymes in energy metabolism. Aquaculture, 93, 357-372 (1991).

7) T. Shikata, D. Kheyyali, and S. Shimeno: Effect of feeding rates on hepatopancreatic enzymes and body composition in common carp. Nippon Suisan Gakkaishi, 59, 835-839 (1993).

8) T. Shikata, T. Masumoto, and S. Shimeno: Metabolic response to restricted feeding of a high protein diet in common carp. Nippon Suisan Gakkaishi, 59, 1587-1591 (1993).

9) T. Shikata, S. Iwanaga, and S. Shimeno: Metabolic response to acclimation temperature in carp. Fisheries Sci., 61, 512-516 (1995).

10) S. Shimeno, T. Shikata, and S. Iwanaga: Changes in the concentrations of glycolytic intermediates and nucleotides and their relation to phosphofructokinase activity in the liver of yellowtail. Suisanzoshoku, 41, 535-539 (1993).

11) S. Shimeno, H. Hosokawa, M. Takeda, S. Takayama, A. Fukui, and H. Sasaki: Adaptation of hepatic enzymes to dietary lipid in young yellowtail. Nippon Suisan Gakkaishi, 47, 63-69 (1981).

12) D. B. Duncan: Multiple range and multiple F test. Biometrics, 11, 1-42 (1955)

13) H. Lin, D. R. Romsos, P. I. Tack, and G. A. Leveille: Effects of fasting and feeding various diets on hepatic lipogenic enzyme activities in coho salmon (Oncorhynchus kisutch (walbaum)). J. Nutr., 107, 1477-1483 (1977).

14) H. Lin, D. R. Romsos, P. I. Tack, and G. A. Leveille: Influence of diet on in vitro and in vivo rates of fatty acid synthesis in coho salmon (Oncorhynchus kisutch (walbaum)). J. Nutr., 107, 16771682 (1977).

15) K. Jürss and R. Bastrop: Amino acid metabolism in fish, in "Biochemistry and Molecular Biology of Fishes" (ed. by P. W. Hochachka and T. P. Mommsen), Vol. 4, Elsevier Science, Amsterdam, 1995, pp. 159-189.

16) R. J. Henderson and J. R. Sargent: Lipid biosynthesis in rainbow trout, Salmo gairdneri, fed diets of differing lipid content. Comp. Biochem. Physiol., 69C, 31-37 (1981).

17) M. Nagai and S. Ikeda: Carbohydrate metabolism in fish-III. Effect of dietary composition on metabolism of glucose-U- ${ }^{14} \mathrm{C}$ and glutamate-U-14 C in carp. Nippon Suisan Gakkaishi, 38, 137-143 (1972).

18) M. Nagai and S. Ikeda: Carbohydrate metabolism in fish-IV. Effect of dietary composition on metabolism of acetate-U- ${ }^{14} \mathrm{C}$ and L-alanine-U- ${ }^{14} \mathrm{C}$ in carp. Nippon Suisan Gakkaishi, 39, 633-643 (1973). 